\title{
AN EXPERIMENTAL STUDY OF WAVE AND CURRENT-INDUCED FORCES ON A COMPACT LINEAR ARRAY OF VERTICAL CYLINDERS IN SHALLOW WATER
}

\author{
Mohamed Kudeih ${ }^{1}$ Andrew Cornett ${ }^{2}$, and Ioan Nistor ${ }^{3}$
}

\begin{abstract}
Arrays of vertical cylinders are essential components of many coastal structures, such as bridge piers, platform legs, and pile breakwaters. Thus, estimating the maximum wave and current-induced forces and moments on such structures is most important. Following a thorough literature review, the authors proceeded with an experimental study in order to investigate the forces exerted by random waves and a superimposed current on an array of three vertical cylinders as a function of the inter-cylinder gap and the angle of wave incidence over a wide range of wave and current conditions in shallow water.
\end{abstract}

Keywords: laboratory experiments; physical modeling; hydrodynamic forces; cylinders; arrays

\section{INTRODUCTION}

Vertical cylinders are essential components of many coastal structures; such as bridge piers, offshore platform legs, and pile breakwaters. Thus, estimating the maximum wave-induced forces and moments on such structures is critical.

Numerous previous studies have investigated theoretically and experimentally the wave-induced forces acting on a single cylinder in shallow water, where the wave forces may be estimated based on the well-known Morison equation with kinematics from a suitable shallow water wave theory. On the other hand, quite a few studies have investigated theoretically the wave-induced forces acting on array of circular cylinders (Massel, 1976), (Iskandarani and Liu, 1988) and (Linton and McIver, 1996). However, most of these studies have ignored flow separation. However, (Kakuno et al., 1996) derived a formula for computing wave forces acting perpendicularly on an array of vertical cylinders based on Kakuno and Liu's perturbation theory (Kakuno and Liu, 1993), where the distance between two adjacent cylinders was assumed to be smaller than the wave length of the incident wave such that flow separation and hence energy dissipation are taken into account. The formula was verified using square cylinders and it showed good agreement with experimental data.

Recently, Suh et al. (2006) developed a numerical model to predict the hydrodynamic characteristics of a pile-supported vertical wall breakwater, comprised of an impermeable vertical barrier near the waterline supported by a linear array of vertical piles. The model was validated using large-scale laboratory experiments using both regular and irregular waves. However, the developed model is limited, since in the case of no breakwater on top, the maximum horizontal wave force per unit width of the breakwater becomes zero.

In this paper, the results of an experimental study on random wave- and current-induced hydrodynamic forces exerted on an array of vertical cylinders in shallow water are presented. The influences of inter-cylinder gap and wave heading are investigated over a wide range of wave and current conditions.

\section{EXPERIMENTAL SETUP}

A series of experiments was carried out in the Large Wave Flume (Fig. 1) at the Canadian Hydraulics Centre, National Research Council of Canada (NRC-CHC), in Ottawa, Canada. The flume is $97.0 \mathrm{~m}$ long, $2.0 \mathrm{~m}$ wide, and up to $2.7 \mathrm{~m}$ deep. The general arrangement of the experimental setup is illustrated in Fig. 2. A scale model of an array of three vertical cylinders was installed at the main test section, $50.0 \mathrm{~m}$ away from the wave generator, where the flume walls are fitted with large viewing windows. The cylinder array was installed on top of an existing concrete sub-floor, which was $1.0 \mathrm{~m}$ high and level at the viewing windows. The sloping foreshore in front of the main test section is $15.0 \mathrm{~m}$ long at a grade of 1:30.

${ }^{1}$ Graduate student, Department of Civil Engineering, University of Ottawa, 161 Louis Pasteur CBY A106, Ottawa ON, K1N 6N5, Canada

${ }^{2}$ Group Leader, Hydrotechnical Engineering, NRC Canadian Hydraulics Centre, and Adjunct Professor, Department of Civil Engineering, University of Ottawa, 1200 Montreal Road, Building M32, Ottawa, ON, K1A OR6, Canada

${ }^{3}$ Associate Professor, Department of Civil Engineering, University of Ottawa, 161 Louis Pasteur CBY A106, Ottawa, ON, K1N 6N5 

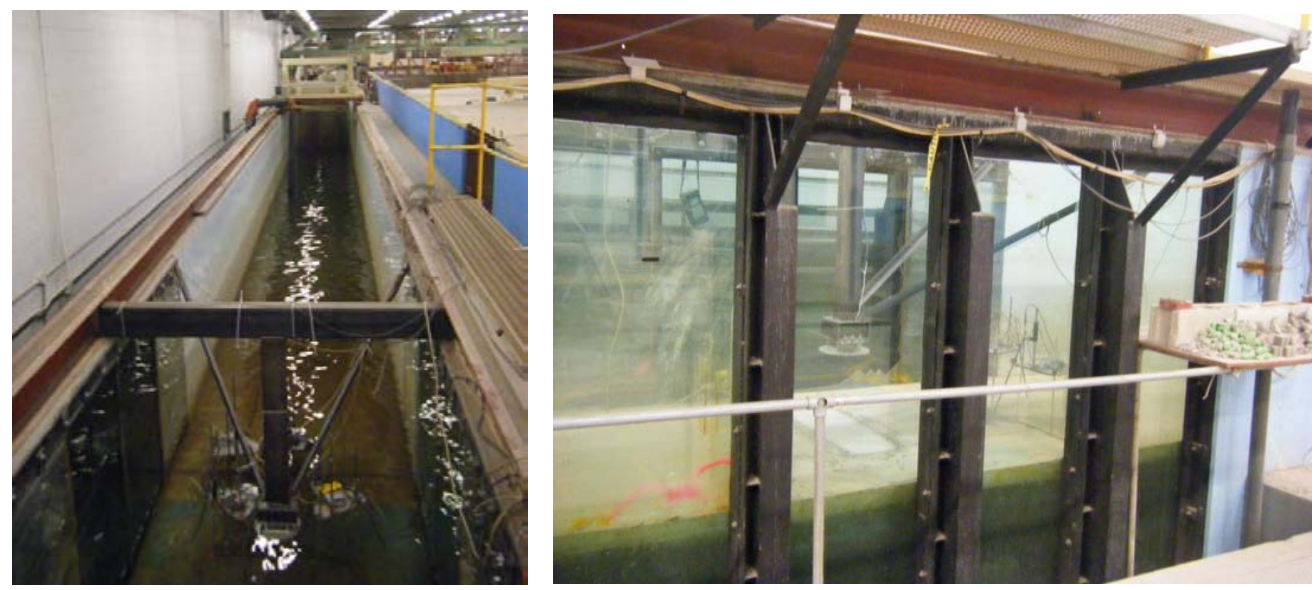

Figure 1. Large wave flume (left), and viewing windows at the main test section (right).

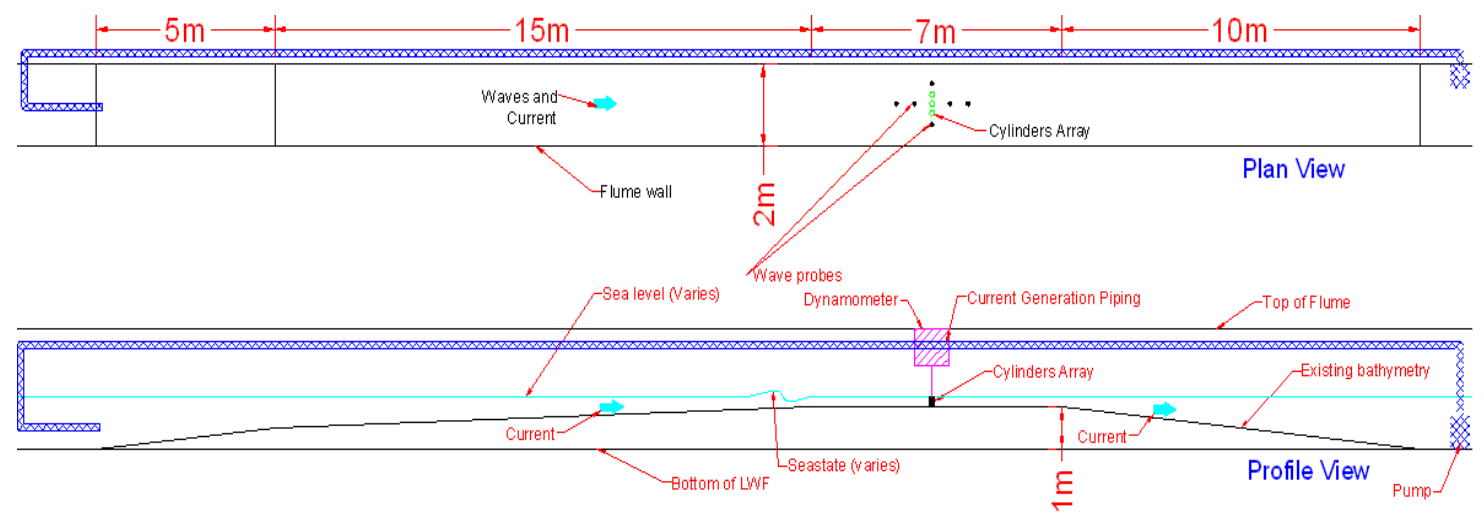

Figure 2. Sketch of the experimental setup.

Random waves required for the experimental program were generated using a piston-type wave machine located at one end of the flume, and absorbed by a progressive wave absorber installed at the other end of the flume. The wave absorber features reflection coefficients below $5 \%$ over a broad range of water depth, wave steepness, and wave height. Capacitance wave gauges were used to measure the wave conditions at the test section.

The flume was also equipped with a simple pumping system to generate the currents required for the experimental program. The system consisted of a single submersible pump located in the flume and positioned downstream from the test section, a discharge outlet located on the bottom of the flume and positioned well upstream from the test section, and a pipeline located outside the flume connecting the pump to the discharge outlet. The discharge, and thus the current velocity at the test site, was regulated by means of a valve and measured using an acoustic flowmeter mounted on the pipeline. A pair of twoaxis electromagnetic current meters was used to measure the wave and current kinematics (in the horizontal plane) at the test section.

The installation of the model cylinder array and the force measuring system is illustrated in Fig. 3 and Fig. 4. Each cylinder was $h=343 \mathrm{~mm}$ tall and $D=145 \mathrm{~mm}$ in diameter, and was made of rigid polystyrene foam reinforced with fiberglass. The cylinders were rigidly suspended from a six-axis dynamometer, which in turn was mounted to a sturdy steel support frame that was braced to the flume walls. The system used to connect the cylinders to the dynamometer made it easy to change the spacing between the cylinders, and change the orientation of the cylinder array within the flume. In this study, tests were conducted with a single cylinder and with arrays of three cylinders with inter-cylinder spacing, $S=D, 1 / 2 D, 1 / 4 D, 1 / 8 D$ and 0 . Wave headings of $\theta=0^{\circ}, 30^{\circ}, 60^{\circ}$ and $90^{\circ}$ were also investigated. The different geometric parameters of the cylinder arrays used in the experimental program are given in Table 1 . The cylinders were positioned approximately $5 \mathrm{~mm}$ above the bottom of the flume, and all the hydrodynamic loads exerted on the cylinder array were transferred to and sensed by the dynamometer. 


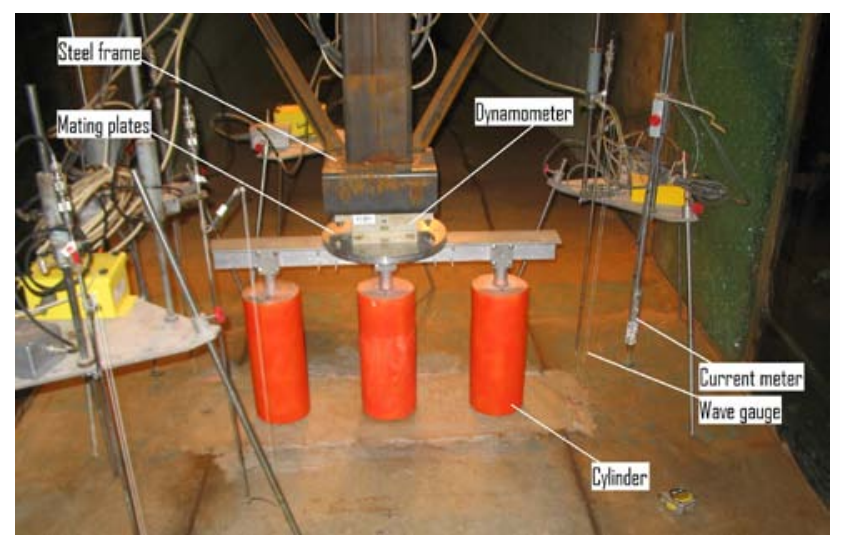

Figure 3. Cylinder array (with spacing $D$ ) and force measurement system.

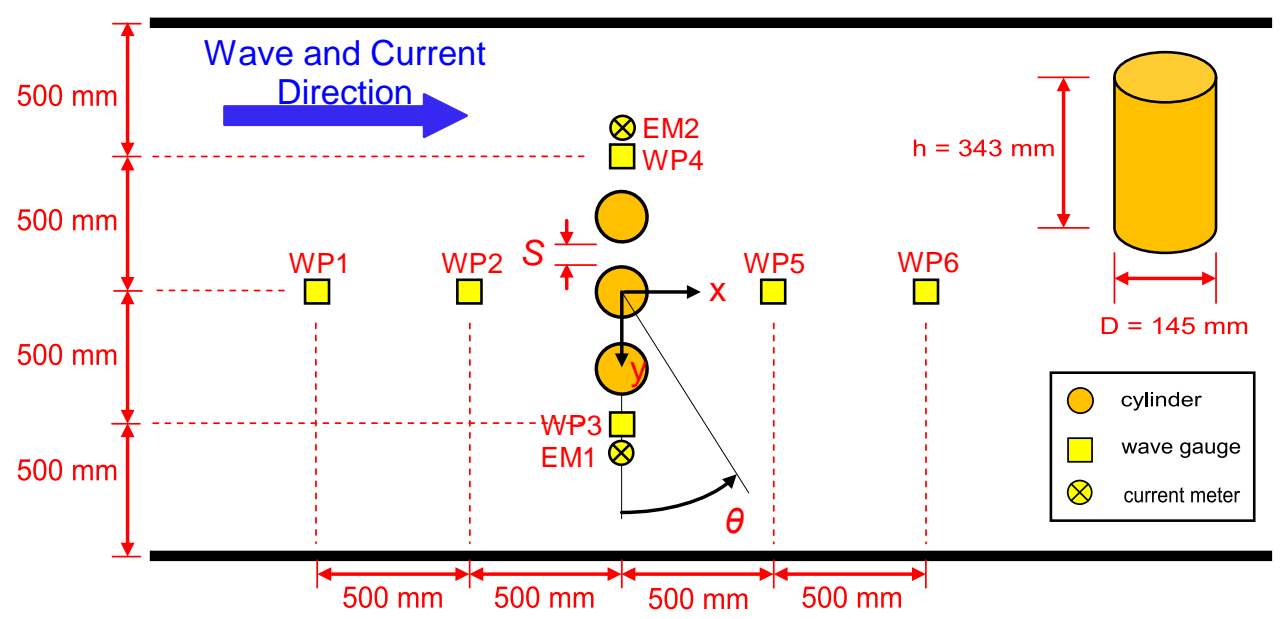

Figure 4. Sketch of instrument layout at the test site.

\begin{tabular}{|ccc|}
\hline \multicolumn{3}{|c|}{ Table 1. Geometric parameters of the cylinders array } \\
\hline Case ID & $S / D$ & $\theta\left(^{\circ}\right)$ \\
\hline R & Single cylinder & - \\
\hline A0 & & 0 \\
A30 & 1 & 30 \\
A60 & & 60 \\
A90 & & 90 \\
\hline B0 & & 0 \\
B30 & $1 / 2$ & 30 \\
B60 & & 60 \\
B90 & & 90 \\
\hline C0 & & 0 \\
C30 & $1 / 4$ & 30 \\
C60 & & 60 \\
C90 & & 90 \\
\hline D0 & 0 \\
D30 & & 30 \\
D60 & $1 / 8$ & 60 \\
D90 & & 90 \\
\hline E0 & & 0 \\
E30 & & 30 \\
E60 & & 60 \\
E90 & 0 & 90 \\
\hline
\end{tabular}




\section{Instrumentation Systems and Data Acquisition}

Six capacitance wave gauges (WP1-WP6) were installed to measure the water surface elevation and hence wave conditions around the test section. The gauges were calibrated often throughout the experimental program by translating them vertically relative to a fixed water level. In all cases, the maximum error was always less than $\pm 0.5 \%$ of the calibration range.

A pair of two-axis electromagnetic current meters (EM1-EM2) was used to measure wave and current kinematics at the test section in the horizontal plane. Both current meters were calibrated in a tilting flume against an acoustic flowmeter over a range of velocities prior to the experimental program. The response of both instruments was stable and linear.

In the case of tests with waves alone, the current meters measured the orbital velocities under the waves. In the case of tests with current alone, they measured the steady current and the fluctuation due to turbulence. In the case of tests with waves and currents acting together, they measured the current (a low frequency signal), the turbulent fluctuations, and the wave-induced orbital velocities (higher frequency signals). When analyzing the velocity measurements, the signals were first split into low frequency and high frequency parts. All oscillations with periods longer than $5.0 \mathrm{~s}$ were assigned to the low frequency category (the current), while all oscillations with periods shorter than $5.0 \mathrm{~s}$ were assigned to the high frequency category (orbital velocities). The data suggested that turbulent fluctuations were present in both low and high frequency bands.

A six-axis dynamometer manufactured by AMTI Corp. (model MC6) was used to measure the hydrodynamic forces and moments exerted on the cylinder array. The dynamometer is capable of sensing forces and moments in three dimensions. The dynamometer was mounted to a custom-built rigid steel frame. The steel frame provided support for the dynamometer at the desired location above the centerline of the flume at the test section. The precision of the force measurement system was checked and verified prior to testing by applying known forces in various directions. The difference between the applied and measured forces and moments was generally less than $2.0 \%$

The natural free vibration frequencies of the force measurement system (including the cylinder array) were checked in air and found to be greater than $75 \mathrm{~Hz}$. This frequency is many times greater than the highest wave frequencies encountered in these experiments, and confirmed that the measurement system was more than adequate for the purpose.

The coordinate system adopted for this experimental program is sketched in Fig. 5. The origin of the dynamometer is located at point $A, 537 \mathrm{~mm}$ above the flume bottom. The six components of force and moment measured at the origin of the dynamometer are defined as:

$F_{X}$ - Horizontal force in the direction of wave propagation

$F_{y}$ - Horizontal force transverse to the direction of wave propagation

$F_{z}-$ Vertical force (positive downward)

$M_{x}-$ Moment at the origin of the dynamometer about the x-axis

$M_{y}$ - Moment at the origin of the dynamometer about the y-axis

$M_{z}$ - Moment at the origin of the dynamometer about the z-axis
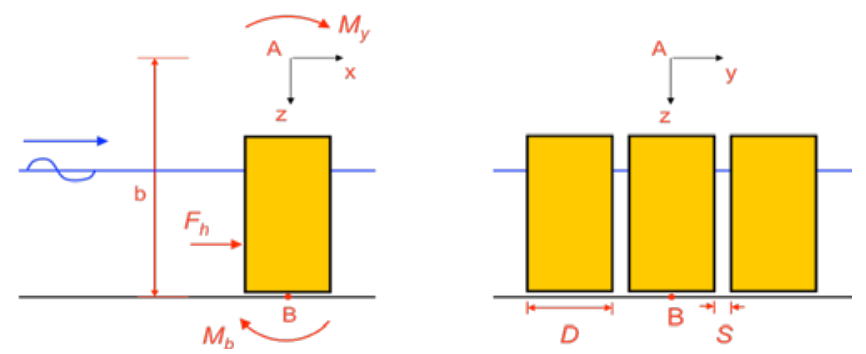

Figure 5. Definition sketch for computing forces and moments. 


\section{Experimental Program}

The cylinder arrays were exposed to the twelve different irregular wave conditions shown in Table 2. Some of the wave conditions were repeated in combination with a collinear following current, flowing with a mean velocity $\left(U_{\mu}\right)$ of $0.15 \mathrm{~m} / \mathrm{s}$. The waves were synthesized from JONSWAP spectra with peak periods $\left(T_{p}\right)$ of 1.0, 1.5, 2.0 and $2.5 \mathrm{~s}$, and significant wave heights $\left(H_{m 0}\right)$ of 0.06 and $0.10 \mathrm{~m}$. Each irregular wave condition was $1200 \mathrm{~s}$ long and, depending on the peak period, contained from 584 to 1277 unique waves. The water depth for all tests was $250 \mathrm{~mm}$ (or 1.72D).

An initial series of tests was conducted to tune and verify the incident wave conditions and undisturbed currents that were realized at the main test section without the cylinder array. No cylinders were installed during these tests. The command signals used to drive the wave machine were adjusted so that the average value of the spectral significant wave height, $H_{m 0}$, and peak period, $T_{p}$, measured at gauges WP2-WP5 were both in close agreement with the specified target conditions. Similarly, the current discharge was adjusted until the average value of the mean velocity measured at gauges EM1EM2 was in good agreement with specified values. The current meters were installed to measure velocities at mid-depth. For wave and current acting together, the wave machine command signals were also adjusted in order to maintain the specified wave height and peak period.

\begin{tabular}{|c|ccc|}
\hline \multicolumn{4}{|c|}{ Table 2. Incident wave conditions and current at the main test section } \\
\hline Test ID & $T_{p}(\mathrm{~s})$ & $H_{m 0}(\mathrm{~m})$ & $U(\mathrm{~m} / \mathrm{s})$ \\
\hline W1 & 1.0 & 0.06 & - \\
W3 & 1.5 & 0.06 & - \\
W4 & 1.5 & 0.10 & - \\
W5 & 2.0 & 0.06 & - \\
W6 & 2.0 & 0.10 & - \\
W7 & 2.5 & 0.06 & - \\
W8 & 2.5 & 0.10 & - \\
W9 & 1.5 & 0.06 & 0.15 \\
W11 & 2.5 & 0.06 & 0.15 \\
\hline
\end{tabular}

Following the flow calibrations, the cylinder array assembly was installed at the main test section of the flume and mounted to the six-axis force measurement system. As mentioned previously, tests were conducted with a single circular cylinder and on arrays of three cylinders with various inter-cylinder gaps and wave directions. A total of 155 different cases were studied in these experiments.

\section{DATA ANALYSIS}

During each test, data from the wave gauges, current meters, and the dynamometer were collected using NDAC data-acquisition and experiment control software, developed by CHC, and analyzed using programs from the GEDAP software library, also developed by CHC. The forces and moments were sampled at $200 \mathrm{~Hz}$, while the waves and kinematics were sampled at $20 \mathrm{~Hz}$. Since the sampling began when the wave board started moving, the first 90 s of each sample were discarded from analysis to remove transient conditions while the first waves propagated down the flume to the test site.

Since the force measurement system was both stiff and lightweight, the natural free vibration frequencies were greater than $75.0 \mathrm{~Hz}$. Thus, any inertial forces that might arise due to vibration of the cylinder array could be separated from the hydrodynamic induced forces, which occurred at frequencies below $2 \mathrm{~Hz}$. Such forces were removed during analysis by digital low-pass filtering the output signals from the dynamometer with a cut-off frequency of $2.0 \mathrm{~Hz}$.

The total horizontal force, $F_{h}$, acting on the cylinder array was obtained from the vector summation of $F_{x}$ and $F_{y}$ as

$$
F_{h}=\sqrt{F_{x}^{2}+F_{y}^{2}}
$$

The overturning moment referenced to flume bed level, $M_{b}$, is given by

$$
M_{b}=b F_{x}-M_{y}
$$


where $b$ is defined as the distance between the origin of the dynamometer located at point $A, 537 \mathrm{~mm}$ above the flume bed, and the seabed level at point $B$ (see Fig. 5)

Figure 6 illustrates a plot of the computed time histories of the total horizontal force and overturning moment. Simple statistics (mean, standard deviation, minimum and maximum values) were computed from the time histories of the measured and derived forces and moments for each test. Furthermore, the maximum observed forces and moments have been plotted as a function of the wave condition, the inter-cylinder gap, and wave heading or direction of wave incidence.

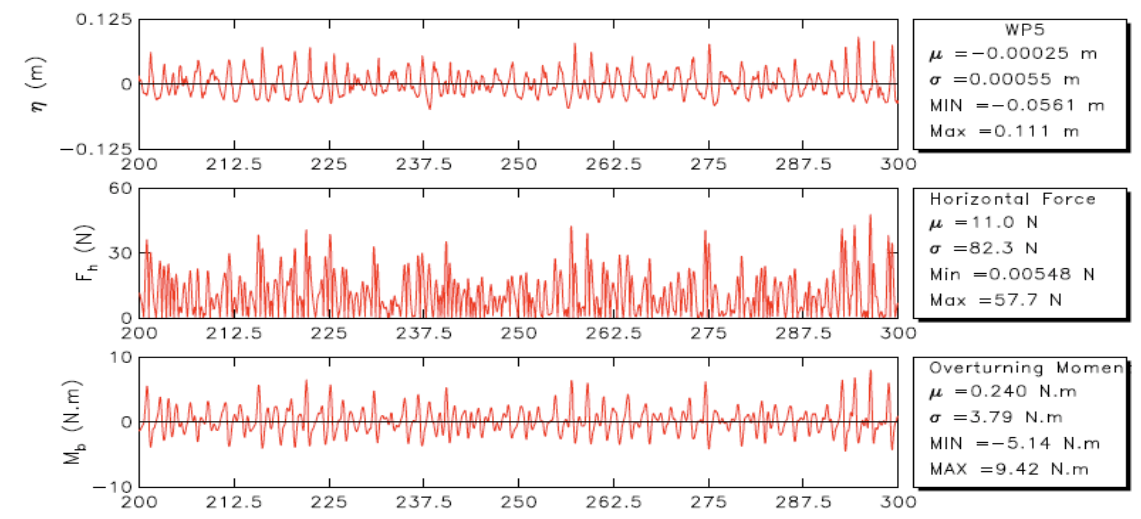

Figure 6. Time histories of the computed $F_{h}$ and $M_{b}\left(S=D, \theta=0^{\circ}, T_{p}=2.0 \mathrm{~s}\right.$, and $\left.H_{m 0}=0.10 \mathrm{~m}\right)$

\section{RESULTS AND DISCUSSION}

The hydrodynamic forces and moments acting on the cylinder arrays were measured and analyzed as described in the previous sections.

Figures 7 and 8 show the relationships between maximum measured horizontal force, $F_{h}$, and maximum overturning moment, $M_{b}$, as a function of the inter-cylinder spacing parameter $S / D$ for various wave conditions and wave headings. For the same wave conditions, the maximum observed total horizontal force and overturning moment varied significantly; in terms on inter-cylinder spacing, they tend to increase as the gap width becomes smaller as expected. The total horizontal force and moment tend to have a mild magnitude gradient for $(1 / 4<S / D<1)$, followed be a rapid linear increase as $(S / D<1 / 4)$. However, the variation in observed force and moment is almost negligible for $\left(\theta>60^{\circ}\right)$, irrespective of the spacing between the cylinders.

As seen in Figure 9, where the observed total horizontal force on the array is normalized by the total horizontal force acting on a single isolated cylinder, there is an increase on the total force on the array of three closely spaced cylinders compared to three isolated cylinders. The force on a compact array of three cylinders can reach to 8 times the force acting on a single cylinder alone.

The effect of a superimposed current of $0.15 \mathrm{~m} / \mathrm{s}$ was also investigated for several configurations and wave conditions. An increase in the force in the range of $10 \%$ and $20 \%$ was observed for waves with peak periods $1.5 \mathrm{~s}$ and $2.5 \mathrm{~s}$ consequently. 

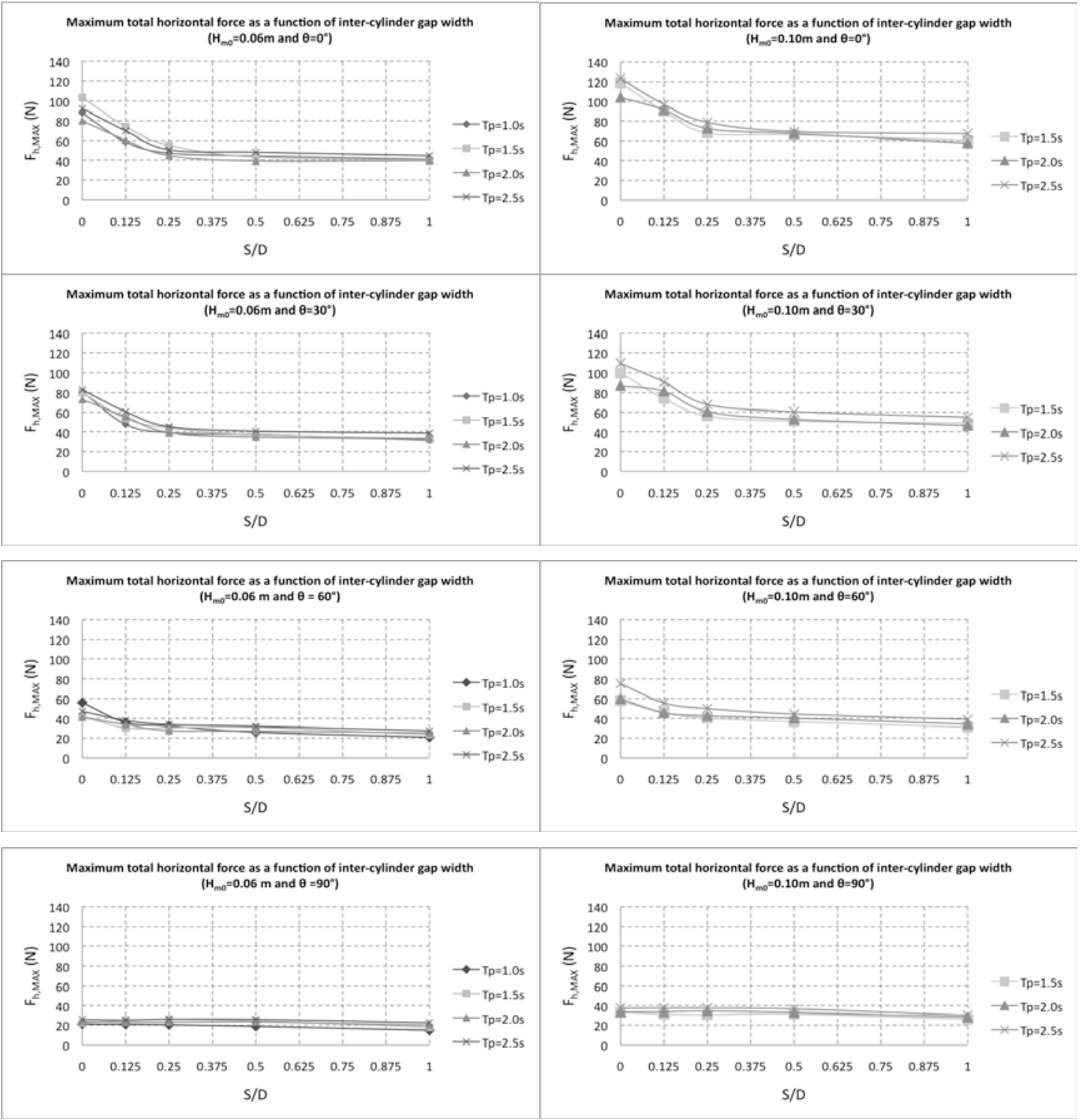

Figure 7. Maximum observed horizontal force as a function of inter-cylinder gap. 

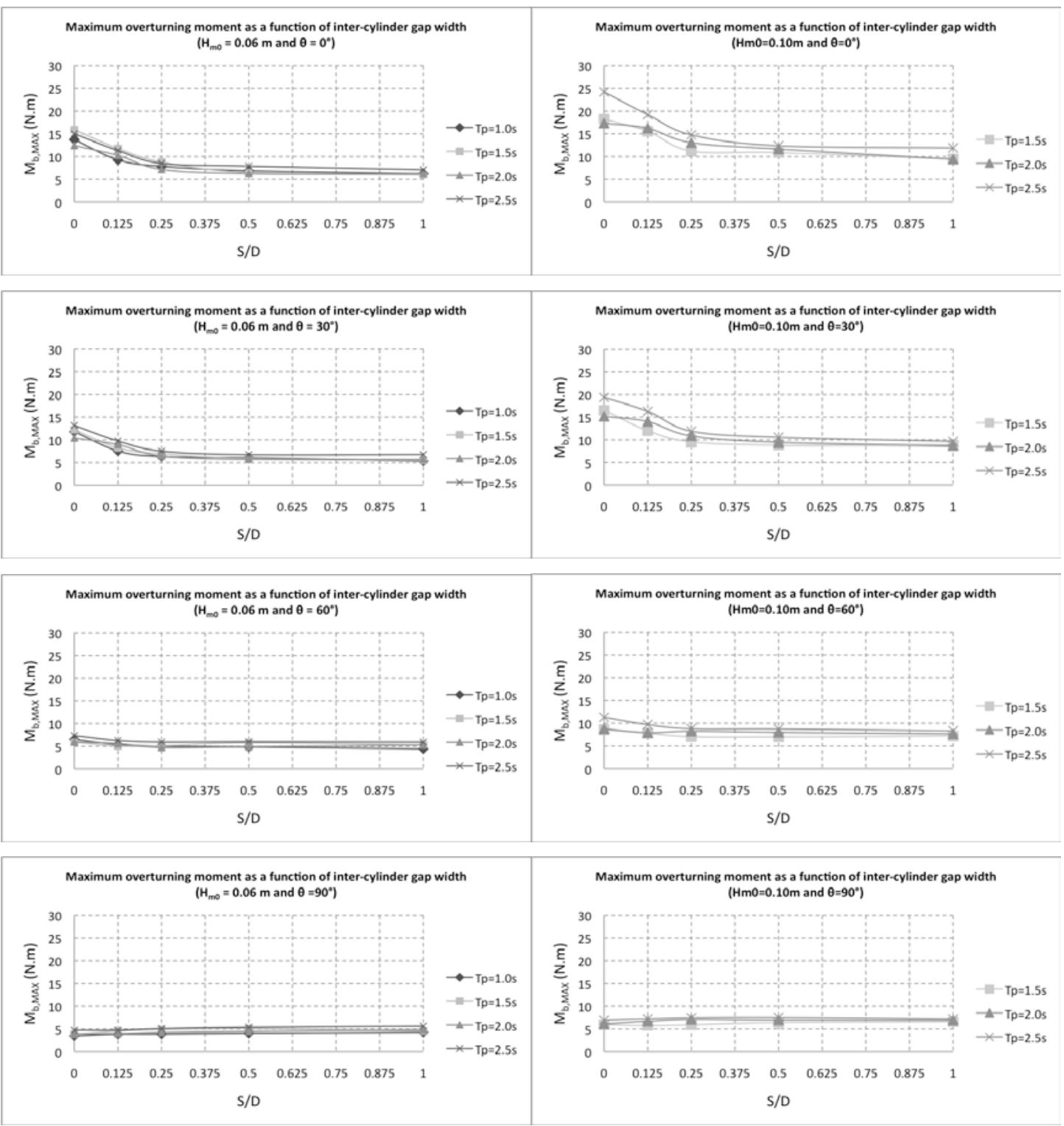

Figure 8. Maximum observed overturning moment as a function of inter-cylinder gap. 

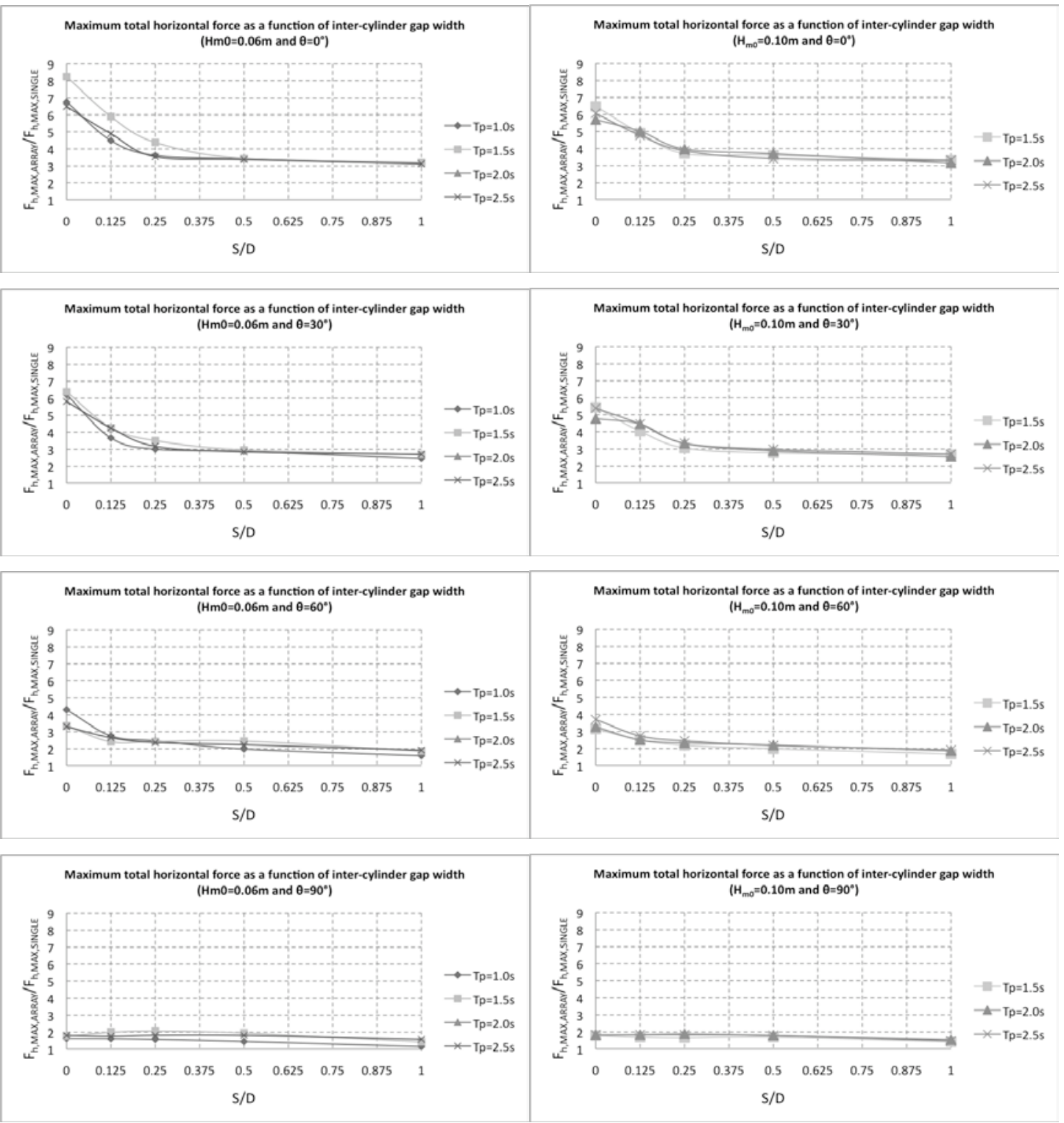

Figure 9. Maximum observed horizontal force on the array to a single cylinder as a function of inter-cylinder gap.

\section{CONCLUSIONS}

In conclusion, an experimental study has been conducted to investigate the hydrodynamic forcing on a compact linear array of three vertical cylinders located in shallow water, due to random waves and currents. The influences of inter-cylinder gap and wave heading have been investigated over a wide range of realistic shallow water wave conditions. For the same wave conditions, the maximum 
horizontal force and maximum overturning moment vary significantly with inter-cylinder gap, increasing significantly as the gap decreases. The rate of force increase is mild for gaps greater than $D / 2$, and much stronger for gaps smaller than $D / 4$. However, the variation in observed force and moment with inter-cylinder gap is almost negligible for $\left(\theta>60^{\circ}\right)$, irrespective of the spacing between the cylinders. In addition, when the total horizontal force acting on an array of three cylinders is significantly larger than the case of three isolated cylinders.

\section{ACKNOWLEDGMENTS}

The authors would like to express their sincere appreciation to the Canadian Hydraulics Centre, National Research Council of Canada (NRC-CHC), in Ottawa, Canada and their staff for their support and help throughout this study. The continuous support of the Natural Sciences and Engineering Research Council of Canada is also gratefully acknowledged.

\section{REFERENCES}

Iskandarani, M., and Liu, P. L.-F. 1988. Multiple scattering of surface water-waves and wave forces on cylinder arrays, Applied Ocean Research, 10(4), 170-180.

Linton, C. M., and McIver, P. 1996. The scattering of water waves by an array of circular cylinders in a channel, Journal of Engineering Mathematics, 30, 661-682

Kakuno, S., Nakata, Y., and Liu, P. L.-F. 1996. Wave forces on an array of vertical cylinders, Journal of Waterway, Ports, Coastal, and Ocean Engineering, 122(3), 147-149.

Kakuno, S., and Liu, P. L.-F. 1993. Scattering of water waves by vertical cylinders, Journal of Waterway, Ports, Coastal and Ocean Engineering, 119(3), 302-322.

Massel, S. R. 1976. Interactions of water waves with cylinder barrier, Journal of the Waterways, Harbors and Coastal Engineering Division, 102(2), 165-187.

Suh, K. D., Shin, S., and Cox, D. T. 2006. Hydrodynamic characteristics of pile-supported vertical wall breakwaters, Journal of Waterway, Ports, Coastal and Ocean Engineering, 132(2), 83-96. 